\title{
Reply to: "Letter to the editor: Comparing pace and speed in the pulmonary circulation?"
}

\author{
Michael A. Quail, ${ }^{1}$ Patrick Segers, ${ }^{\mathbf{2}}$ and Vivek Muthurangu ${ }^{1}$ \\ ${ }^{1}$ Centre for Cardiovascular Imaging, Institute of Cardiovascular Science, University College London and Great Ormond

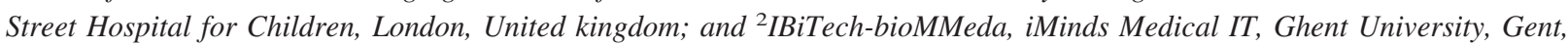 \\ Belgium
}

REPLY: We thank Weir-McCall and colleagues (2) for identifying the typographical error in the equation for wave speed in our appendix (1). Unfortunately the Q and A were inverted in the text. The equation based on energy minimization in the appendix should rather read:

$$
c=\sqrt{\frac{\sum \mathrm{dQ}^{2}}{\sum \mathrm{d} A^{2}}}
$$

which does result in wave speed in $\mathrm{m} / \mathrm{s}$. However, the correct equation was used in processing of the data in the article (Fig. 1A). In fact, if we had calculated "pace," a significant bias would be seen, as shown in Fig. $1 B$.

Weir-McCall rightly draws attention to the difficulty of measuring pulse wave velocity (PWV) in the pulmonary circulation and the relatively wide limits of agreement between the two methods described in the appendix of this study. Unfortunately, there is no noninvasive reference standard method of assessing PWV in the pulmonary circulation. We compared our "three-point Q/A method" of assessing PWV with an alternative energy minimization technique to exclude large biases. The minimal bias suggests that there is no systematic difference between these two techniques. However, the energy minimization technique was developed for the coronary

Address for reprint requests and other correspondence: V. Muthurangu, Level 6 Old Nurses Home, Cardiorespiratory Unit, Great Ormond St. Hospital for Children, Great Ormond St., London, WC1N 3JH, UK (e-mail: v.muthurangu@ucl.ac.uk). circulation, where it is not possible to calculate the PWV using the Q/A method. We believe that in the pulmonary circulation the Q/A method is more valid, which may account for the relatively wide limits of agreement. However, we agree that more work is required in validating these metrics and one possibility is through the use of in silico models.

\section{GRANTS}

The authors acknowledge the support received from the British Heart Foundation and United Kingdom National Institute of Health Research. This report is independent research by the National Institute for Health Research Biomedical Research Centre Funding Scheme. The views expressed in this publication are those of the authors and not necessarily those of the NHS, the National Institute for Health Research, or the Department of Health.

\section{DISCLOSURES}

No conflicts of interest, financial or otherwise, are declared by the author(s).

\section{AUTHOR CONTRIBUTIONS}

M.A.Q. prepared figure; M.A.Q. and V.M. drafted manuscript; M.A.Q. P.S., and V.M. edited and revised manuscript; M.A.Q. and V.M. approved final version of manuscript.

\section{REFERENCES}

1. Quail MA, Knight DS, Steeden a J, Taelman L, Moledina S, Taylor AM, Segers P, Coghlan JG, Muthurangu V. Noninvasive pulmonary artery wave intensity analysis in pulmonary hypertension. Am J Physiol Heart Circ Physiol 308: H1603-H1611, 2015.

2. Jonathan R. Weir-McCall JR, Struthers AD, Lipworth BJ, and Houston JG. Letter to the editor: Comparing pace and speed in the pulmonary circulation? Am J Physiol Heart Circ Physiol 310: H0-H0, 2016. doi: 10.1152/ajpheart.00065.2016.
Fig. 1. A: original figure comparing pulse wave velocity $(\mathrm{PWV})(\mathrm{Q} / \mathrm{A}$ method) with the energy minimization technique. $B$ : Bland Altman comparing PWV (Q/A method) with "pace" based upon the typographical error equation.
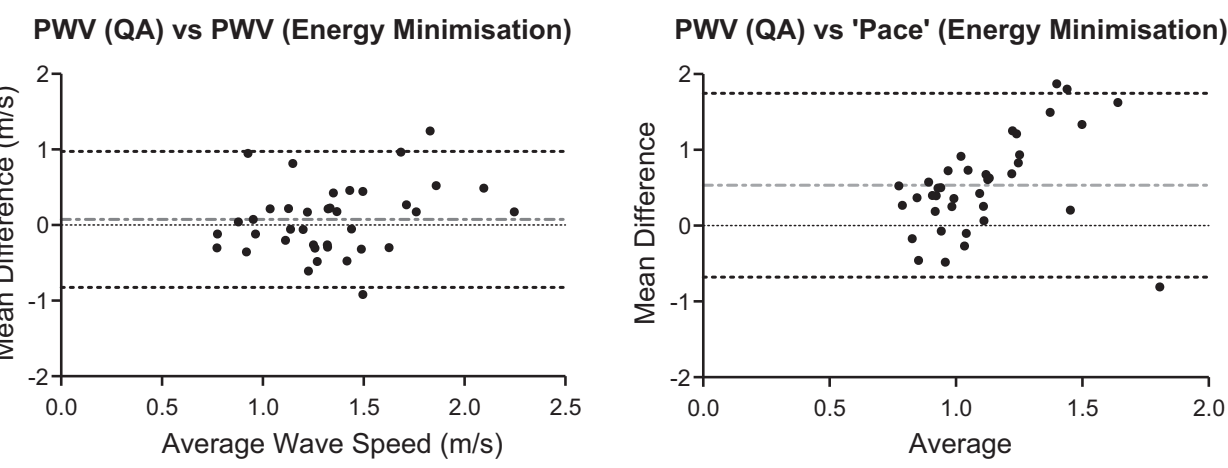